\title{
VALORIZAÇÃO E DINÂMICA SOCIOESPACIAL DO ESPAÇO URBANO: OLHARES SOBRE O ESPIGÃO COSTEIRO NO BAIRRO PONTA D'AREIA EM SÃO LUÍS (MARANHÃO, BRASIL) ${ }^{1}$
}

\author{
VALORACIÓN Y DINÁMICA SOCIOESPACIAL DEL ESPACIO URBANO: \\ LA ESPIGA COSTERA EN EL DISTRITO DE PONTA D'AREIA DE \\ SÃO LUÍS (MARANHÃO, BRASIL)
}

Matheus Andrade MARQUES ${ }^{2}$

\begin{abstract}
Resumo: O presente artigo almeja discutir o processo de valorização e alteração na dinâmica do espaço urbano de São Luís (Maranhão, Brasil), deste modo, estaremos observando nesse estudo essa realidade através do recorte espacial do bairro Ponta d'Areia. Através de uma abordagem mais específica, nossas análises estarão centradas no surgimento do espigão costeiro do referido bairro, fruto de uma obra pública e inaugurado em 2014 visando solucionar alguns problemas vigentes naquele setor da cidade. Porém, após a conclusão do empreendimento, ele torna-se um novo ponto turístico e de lazer da cidade, trazendo assim uma nova dinâmica socioespacial para a área. Portanto, temos como objetivo de pesquisa: analisar como o surgimento do espigão contribuiu para a valorização do bairro e suas eventuais consequências para a população local. O trabalho se estrutura a partir de um momento introdutório de apresentação do objeto de pesquisa; em seguida são elencados os procedimentos metodológicos; no momento posterior dialogamos sobre o surgimento do espigão; na quarta seção trazemos à tona a discussão a respeito das consequências da obra no território; e por fim, tecemos alguns apontamentos sobre os resultados obtidos com a construção do estudo.
\end{abstract}

Palavras-chave: Espigão costeiro; Ponta d'Areia; São Luís.

Resumen: El presente artículo tiene como objetivo discutir el proceso de valoración y cambio en la dinámica del espacio urbano en São Luís (Maranhão, Brasil), por lo que, observaremos en este estudio esta realidad a través del recorte espacial del barrio de Ponta d'Areia. A través de un enfoque más específico, nuestros análisis se centrarán en el surgimiento de la espiga costera del referido barrio, fruto de una obra pública e inaugurada en 2014 con el objetivo de solucionar algunos problemas existentes en ese sector de la ciudad. Sin embargo, tras la finalización de la empresa, se convierte en un nuevo punto turístico y de ocio de la ciudad, aportando así una nueva dinámica socioespacial a la zona. Por lo tanto, tenemos como objetivo de investigación: analizar cómo la aparición de la espiga contribuyó a la valorización del barrio y sus posibles consecuencias para la población local. El trabajo está estructurado a partir de un momento introductorio de presentación del objeto de investigación; a continuación se enumeran los procedimientos metodológicos; en el siguiente momento se discute el surgimiento de la espiga; en el cuarto apartado se trae a colación la discusión sobre las consecuencias del trabajo en el territorio; y finalmente, se hacen algunas anotaciones sobre los resultados obtenidos con la construcción del estudio.

Palabras clave: Espiga costera; Ponta d'Areia; São Luís.

\footnotetext{
${ }^{1}$ Pesquisa financiada pela Fundação de Amparo à Pesquisa e ao Desenvolvimento Científico e Tecnológico do Maranhão - FAPEMA.

${ }^{2}$ Doutorando em Geografia pela Universidade Federal do Ceará. E-mail: marquesm93@ @otmail.com.
} 


\section{Introdução}

A presente pesquisa busca trazer à tona uma discussão sobre o processo de valorização dos espaços urbanos contemporâneos, e como o referido fenômeno interfere na dinâmica socioespacial dos lugares. Para tal, utiliza-se como objeto de investigação a cidade de São Luís (Maranhão, Brasil), mais especificamente, através do recorte espacial de seu espigão costeiro, localizado no bairro Ponta d'Areia.

Segundo Coelho e Sales (2017), está área da cidade foi a que mais se valorizou ao longo dos últimos quinze anos, isto em virtude de ações de construtoras do ramo imobiliário que investiram na construção de inúmeros condomínios de luxo no lugar. No que diz respeito ao espigão costeiro, este é também um dos fatores que contribuíram para a efetivação desse fenômeno, agregando um considerável valor ao território, além de cumprir uma função socioambiental importante.

O espigão é fruto de uma obra pública, que surge com o intuito de conter o avanço marítimo no setor norte da cidade de São Luís, onde localiza-se o bairro Ponta d'Areia. Ele também serve para minimizar processos erosivos, desassorear canais e ajuda na manutenção da faixa de areia da praia Ponta d'Areia, que estava sendo tomada pelo avanço da maré.

Com a inauguração da obra em 2014, observa-se ao longo do tempo os resultados esperados com a intervenção do espigão, mas ocorre também a instauração de novas dinâmicas socioespaciais no local, uma vez que se instala no bairro Ponta d'Areia uma rede comercial de diversos serviços. Acontecem também obras de infraestrutura e urbanização na área, instituindo-se assim, o uso turístico e de lazer daquele espaço.

Em virtude dessas características, o lugar tornou-se "uma excelente opção para a prática de esportes, lazer, passeio e até mesmo para aproveitamento da paisagem para tirar fotos, por exemplo" (SILVA, 2018, p. 22). Em razão dessa conotação de uso do espaço como local turístico e de lazer em São Luís, alguns empreendimentos se instalaram ali, dos mais diversos ramos, como: artesãos, bares, restaurantes, vendedores ambulantes, parques de diversão e outros. Toda essa rede comercial surge com o intuito de atender os novos visitantes do local, ou seja, os consumidores.

Nota-se também que a segurança pública no espigão costeiro e em seu entorno é presente. Fator que proporciona aos visitantes maior sentimento de segurança, realidade que se contrasta com outras áreas da cidade, onde o mesmo aparato não é identificado de forma satisfatória (MARTINS, 2018). Assim, compreende-se que a construção do espigão costeiro, 
ao mesmo tempo que trouxe benefícios para os inúmeros visitantes, também expõe uma realidade existente na Ponta d'Areia que é distinta de outros bairros de São Luís, que é a seletividade na aplicação de determinadas políticas públicas, acredita-se que tal fenômeno está relacionado ao processo de valorização do espaço vigente neste setor da urbe.

A consolidação do espigão costeiro como ponto turístico acabou atraindo além dos novos visitantes ao local, também novas dinâmicas para aquele espaço da cidade. Destarte, temos como objetivo central dessa pesquisa observar este processo, por meio do seu surgimento, assim como identificar as principais consequências para a sociedade de São Luís.

Deste modo, este artigo se estrutura em cinco momentos, inicialmente com essa parte introdutória, apresentando o objeto de pesquisa; em seguida elencamos os procedimentos metodológicos de pesquisa que foram adotados; posteriormente, a discussão é aprofundada com foco no surgimento do espigão costeiro; na sequência, refletimos sobre as consequências da obra para o território; e por fim, realizamos algumas considerações a respeito dos resultados obtidos.

\section{Procedimentos metodológicos}

Os procedimentos metodológicos adotados são caracterizados de acordo com uma pesquisa de viés exploratório, pois, contribuem na ampliação do conhecimento a respeito do objeto de estudo desenvolvido (PIOVESAN e TEMPORINI, 1995). Gil (2006, p. 34) reitera que "as pesquisas exploratórias constituem uma primeira etapa de uma investigação mais ampla". Assim, realizou-se pesquisa bibliográfica em busca de trabalhos (artigos em periódicos, livros e outros) que tratassem da temática central de nossa pesquisa, ou seja, que discutissem a valorização do espaço urbano, com ênfase para a cidade de São Luís.

Para melhor contextualizar o nosso campo de estudo, também foi elaborado um mapa de localização do bairro Ponta d'Areia, conforme demonstra a figura 1: 
EM

Figura 1 - Mapa de Localização do Bairro Ponta ‘Areia.

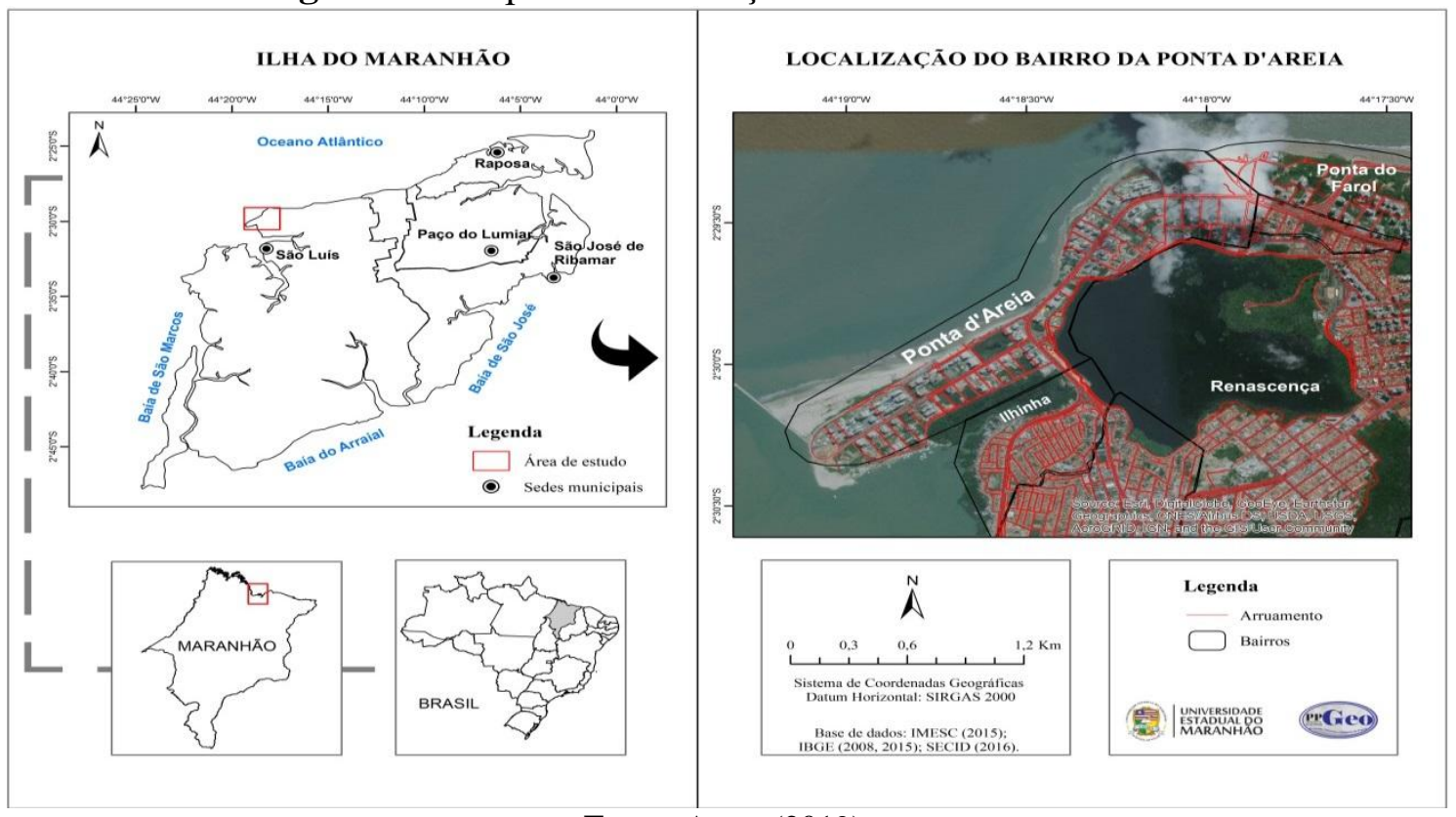

Fonte: Autor (2019).

Posteriormente, foram realizados trabalhos de campo no bairro Ponta d'Areia, com o intuito de observar a dinâmica de uso do espaço atualmente, serviços, estrutura e outros. Também executamos ainda durante a fase de campo, alguns registros fotográficos do local, visando assim, demonstrar/caracterizar o objeto de estudo e demais áreas ao leitor.

Figura 2 - Espigão Costeiro.

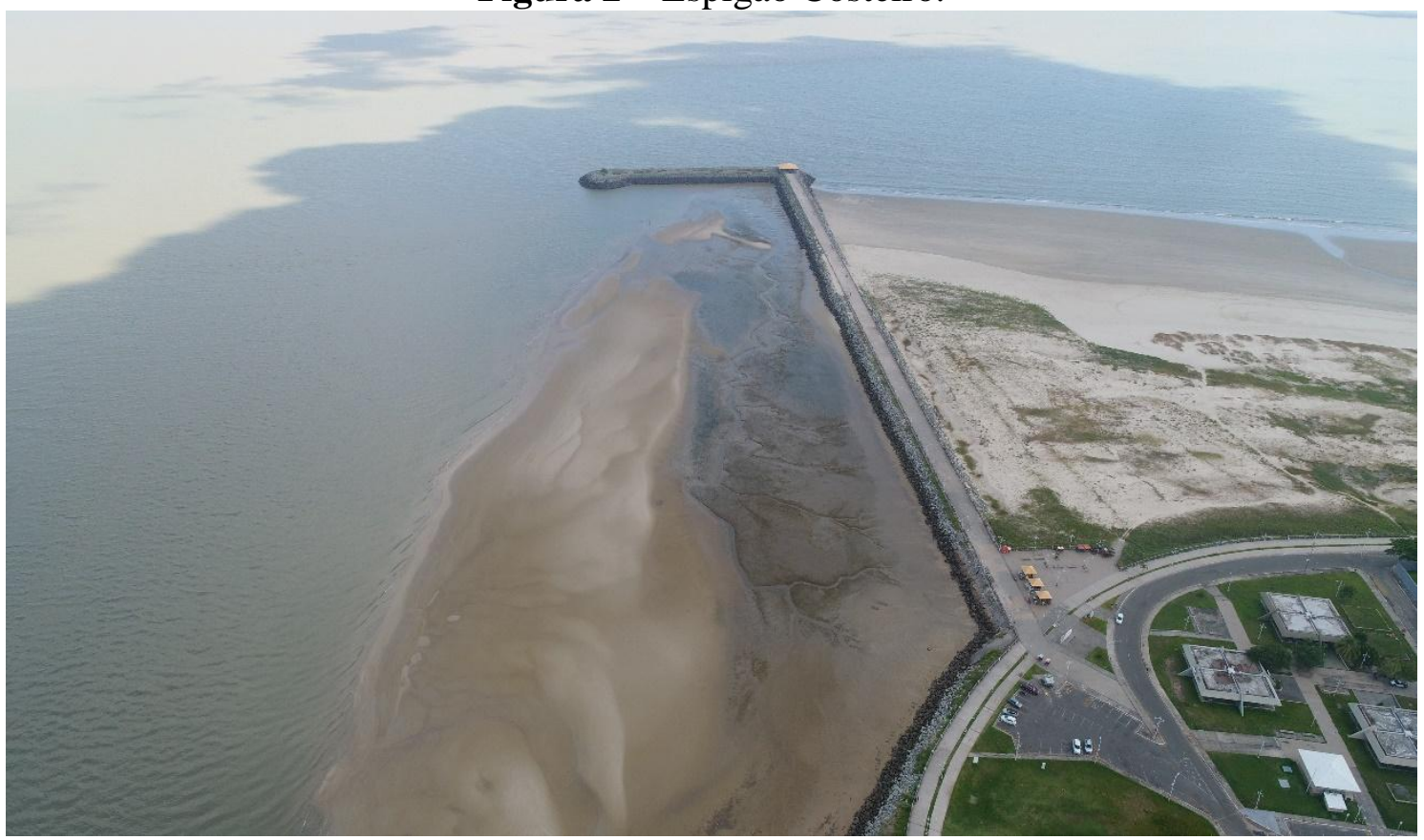

Fonte: Autor (2020). 
EM

A metodologia de análise aplicada se fundamenta a partir de um prisma descritivo, que possui como intuito fundamental, caracterizar a realidade do objeto estudado, portanto, irá nos proporcionar elementos satisfatórios para a execução de uma reflexão a respeito das consequências do surgimento do espigão para a sociedade ludovicense.

\section{Origem do espigão costeiro da Ponta d'Areia}

Convém, mesmo que de forma sintética, destacarmos o processo de formação do bairro Ponta d'Areia, este exercício se mostra relevante para melhor compreensão da necessidade do surgimento do espigão costeiro nessa área. Em função da sua localização na zona costeira da ilha de São Luís, o bairro é integrante de um setor que fora estratégico ao longo da história da capital maranhense (PRADO, 2016).

O atual bairro Ponta d'Areia, cuja forma o próprio nome indica, se configurava em uma estratégica localização para a defesa e proteção da cidade de São Luís, desde o século XVIII. Pode-se dizer que, antes mesmo que o núcleo colonial de São Luís fosse avistado pelos navegantes, era a paisagem da Ponta d'Areia a primeira a ser vista do mar (PRADO, 2016, p. 73).

O Forte surge no território do bairro Ponta d'Areia no final do século XVIII, sendo denominado de Forte de Santo Antonio (figura 3), é um dos grandes marcos do lugar, possuía papel importante para a defesa e proteção da cidade, era gerido por militares.

Figura 3 - Forte de Santo Antonio.

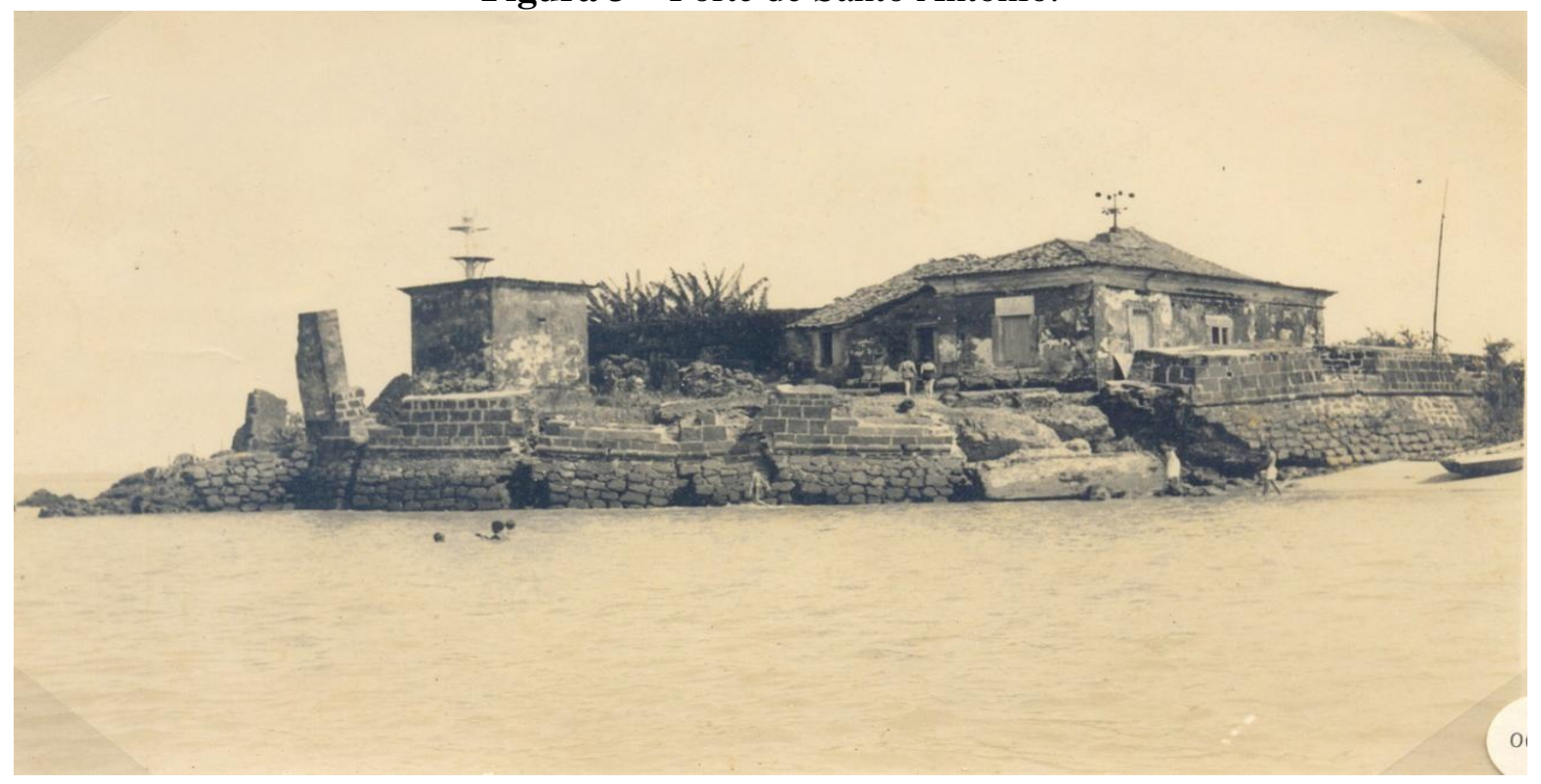

Fonte: Facebook São Luís Antes e Depois (2020). 
EM

Porém, convém salientar que essa ocupação militar não se restringia somente à defesa, mas cabia-lhe também o controle das riquezas que eram exploradas nessa parte da costa ludovicense (PRADO, 2016). Assim, compreende-se que a área onde atualmente localiza-se o bairro Ponta d'Areia, possuía uma relevância ímpar para São Luís por tratar-se de um local estratégico aos mais diversos interesses.

Pode-se observar através da figura 3, que ao entorno do Forte, temos o mar. Essa informação se faz pertinente, em razão dessa área ser a mesma onde atualmente encontra-se localizado o bairro Ponta d'Areia, que ao longo do tempo, através de um intenso processo de aterramento, tornou-se uma área de habitação para a população de São Luís. A figura 4 demonstra o cenário atualmente.

Figura 4 - Forte de Santo Antônio reformado.

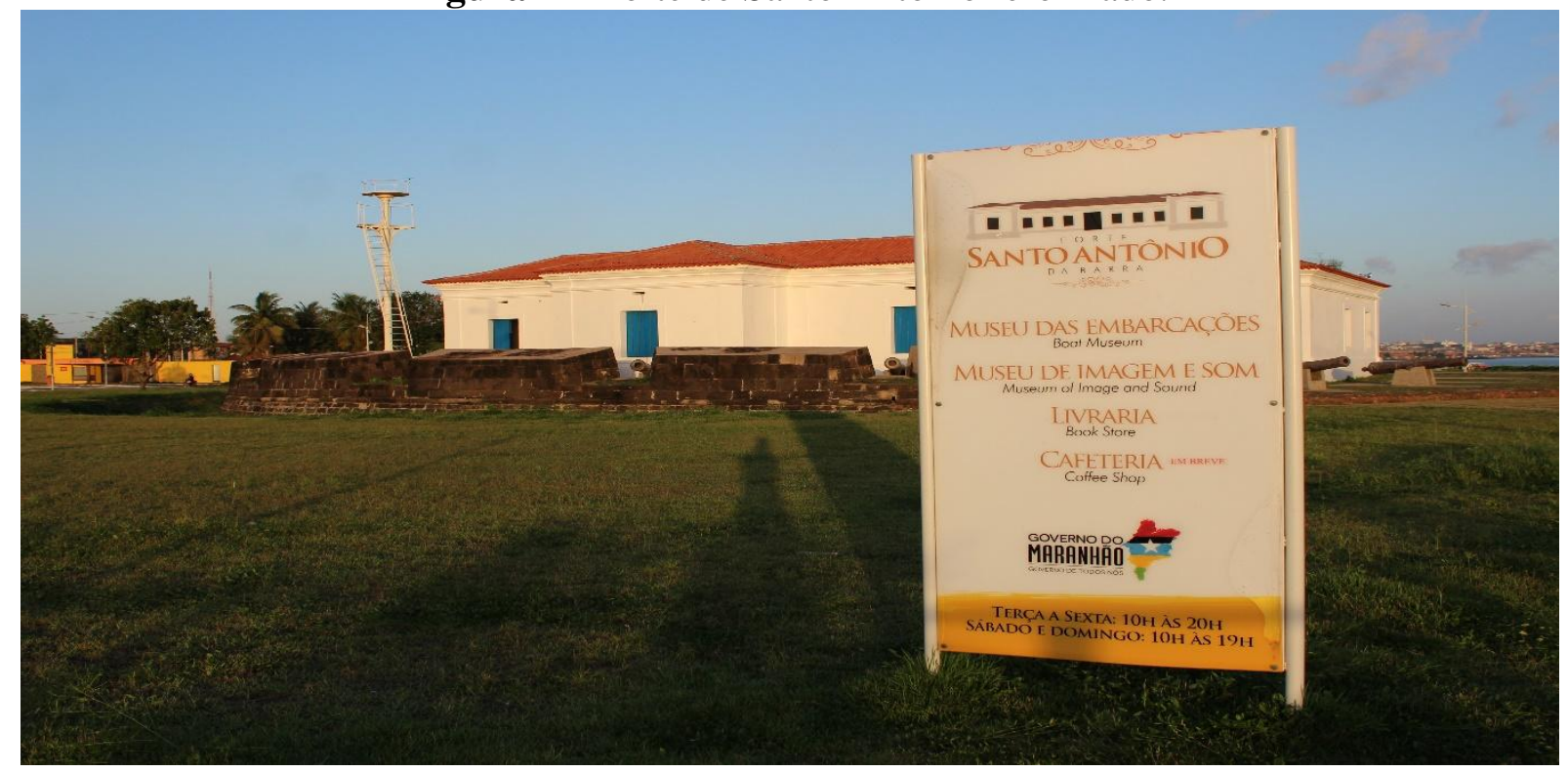

Fonte: Autor (2020).

A figura 4 ratifica a considerável transformação por qual passou esta zona da cidade, nota-se que atualmente o Forte transformou-se após reforma realizada pelo Estado do Maranhão, em um museu, livraria e cafeteria. O entorno do espaço também foi modificado, nota-se que a área foi urbanizada de forma significativa.

Portanto, em função dessa transformação socioespacial que ocorrera no bairro Ponta d'Areia ao longo do tempo, foi necessária a implantação de um espigão costeiro. Essa necessidade surgiu da constatação de um forte avanço marítimo nesse setor da cidade, algo que já foi comum nessa área, como apresentado na figura 3. 
EM

QUESTÃO

V.14 N. $02 \downarrow 2021$

pág. 111-123

E como resultados desse fenômeno de avanço da maré no setor norte da cidade ao longo dos anos, destacamos alguns problemas como o forte processo erosivo (figura 5). Essa situação afeta diretamente a faixa de praia existente no bairro, deteriorando a calçada e assim prejudicando a população local.

Figura 5 - Calçada danificada por processo erosivo na praia Ponta d'Areia.

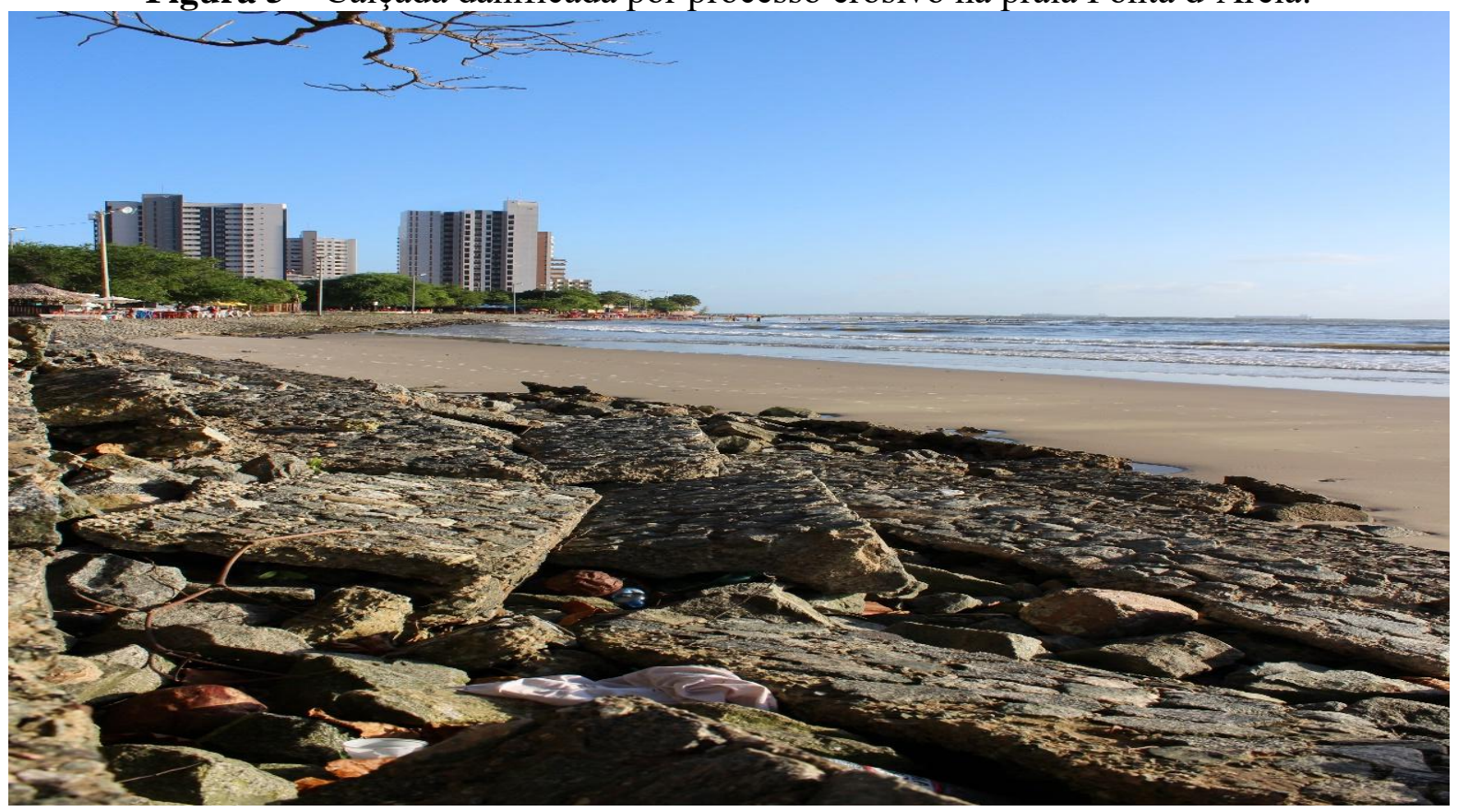

Fonte: Autor (2019).

Em razão dessa realidade, o Governo do Estado do Maranhão construiu o espigão costeiro, visando resolver problemáticas advindas desse processo de avanço do mar, para assim proporcionar melhores condições de uso do espaço para a sociedade. Então, no ano de 2011 são iniciadas as obras para a construção do espigão costeiro de São Luís, sendo findada apenas no ano de 2014, quando ocorreu a sua inauguração.

Segundo a Secretaria de Infraestrutura do Estado do Maranhão (SINFRA) em 2014, o projeto foi orçado no valor de $\mathrm{R} \$ 32$ milhões. E antes mesmo de sua finalização, já era notório a quem passasse pelo local os resultados provenientes da intervenção, iniciou-se um grande acúmulo de areia em um lado do espigão, enquanto de outro lado, estava o mar, que agora já não avança com a mesma intensidade sobre a faixa de praia (figura 6). 
EM

Figura 6 - Resultados da criação do espigão costeiro.

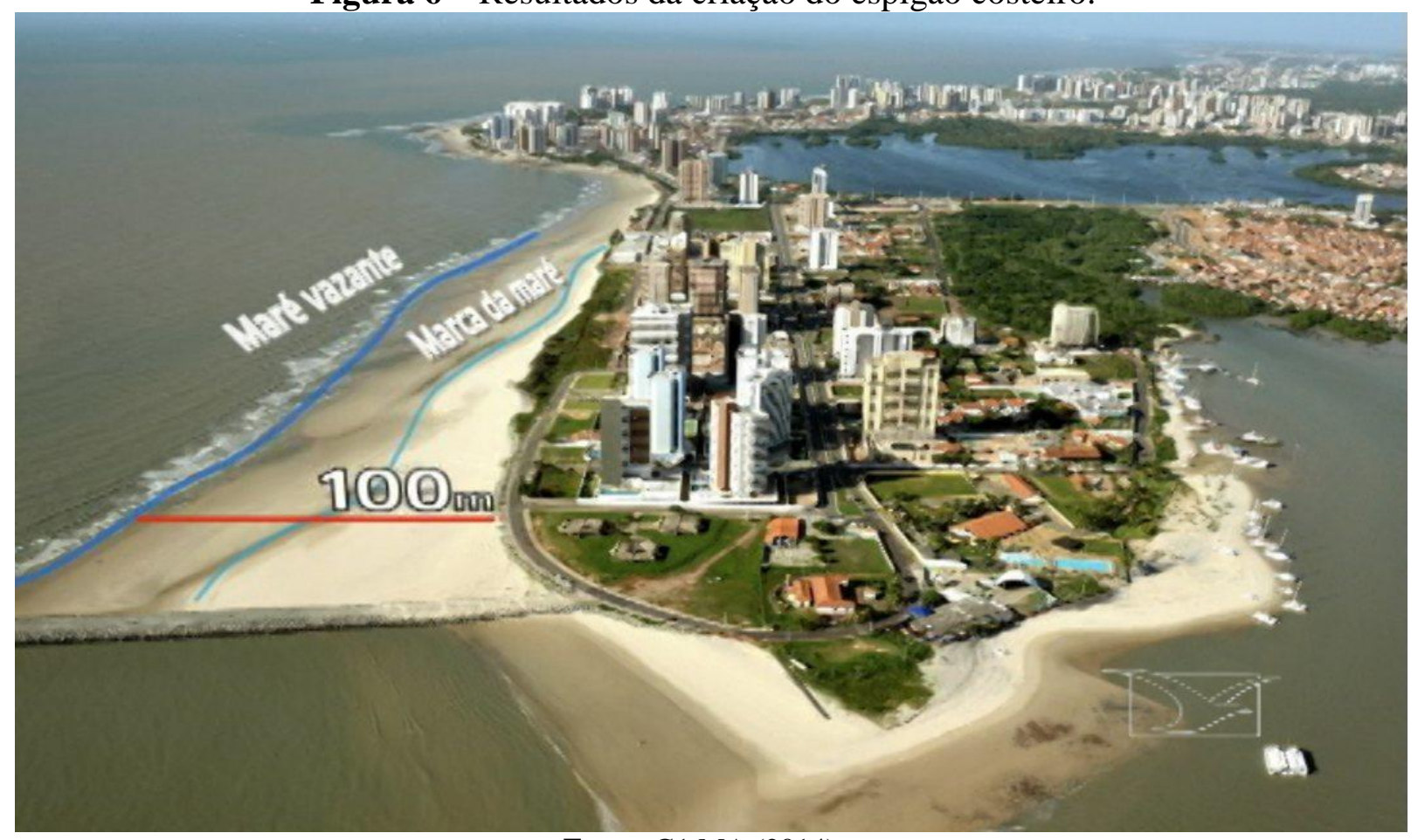

Fonte: G1 MA (2014).

O espigão consegue cumprir a sua finalidade primária, nota-se ao longo dos anos que a faixa de areia da praia volta a ser recuperada, e o processo erosivo na área também diminuiu, uma vez que a obra funciona como uma espécie de medida protetiva para conter o avanço marítimo no local, minimizando assim os impactos no litoral norte da cidade.

Em virtude de uma obra de urbanização do espigão costeiro e instalação de inúmeros serviços no local e no seu entorno, novas atividades surgem no lugar, como os usos turístico e de lazer, que também são incorporados aos benefícios advindos da construção do empreendimento, tendo como consequência a alteração na dinâmica socioespacial da área, logo o espigão deixa de ser apenas uma obra para sanar uma problemática de avanço da maré, e transforma-se também em um local de visitação para a população local e turistas.

\section{A valorização do espaço a partir do espigão costeiro}

Como foi exposto no momento anterior, a dinâmica de uso e ocupação foi alterada no bairro Ponta d'Areia em função do surgimento do espigão costeiro, de sua urbanização e transformação em atrativo turístico e ambiente de lazer. Dessa forma, não somente a configuração paisagística se modificou, mas também outros fatores, o novo empreendimento 
trouxe consigo um agravamento no processo que já existia naquela região da cidade, a valorização do solo urbano.

O referido fenômeno de valorização da área já estava em curso em função, principalmente, do papel desempenhado pela iniciativa privada atuante no território do bairro Ponta d'Areia. Ao longo das últimas duas décadas empresas do ramo imobiliário investiram capital de forma considerável neste setor da cidade, sobretudo no âmbito da construção de inúmeros edifícios de luxo. Portanto, compreende-se que o surgimento desses prédios que compõem a paisagem do referido bairro, juntamente com o fator de moradia em condomínios fechados de alto padrão, são os grandes responsáveis pela valorização do solo urbano da Ponta d'Areia.

Ainda com relação à valorização do espaço, destaca-se que ao longo dos anos o bairro de forma geral tornou-se ainda mais valorizado, também em virtude de aspectos paisagísticos naturais existentes no lugar, como por exemplo, a praia Ponta d'Areia. A sua localização próxima ao centro da cidade é outro ponto relevante.

Destaca-se também o papel desempenhado pelo poder público, através de obras de infraestrutura e outras políticas como a inserção da área como zona turística de São Luís, conforme a lei de zoneamento municipal de 1992. Todos estes fatores foram agregados e potencializaram o processo de valorização socioespacial do bairro.

No que diz respeito ao espigão costeiro, nota-se que o seu surgimento também é fator contribuinte para agregação de valor ao lugar, porém, este fator pode ser observado como mais um elemento integrante desse processo de valorização socioespacial já vigente na área, e não como expoente desse fenômeno. Tal fato se justifica em razão dessa realidade já está em curso antes mesmo da existência do espigão (COELHO e SALES, 2017).

Porém, o espigão costeiro trouxe ao local uma nova dinâmica de uso para aqueles que o frequentam, que foi o uso turístico e também o surgimento de mais uma área de lazer para a população ludovicense (MARQUES, 2021). Isto foi possível em função do papel desempenhado pelo poder público que estruturou a área e contribuiu para a ascensão do turismo e lazer nesse setor da cidade. A figura 7 demonstra o uso por parte da população desse espaço atualmente. 
EM

Figura 7 - Área de lazer e convívio no bairro Ponta d'Areia.

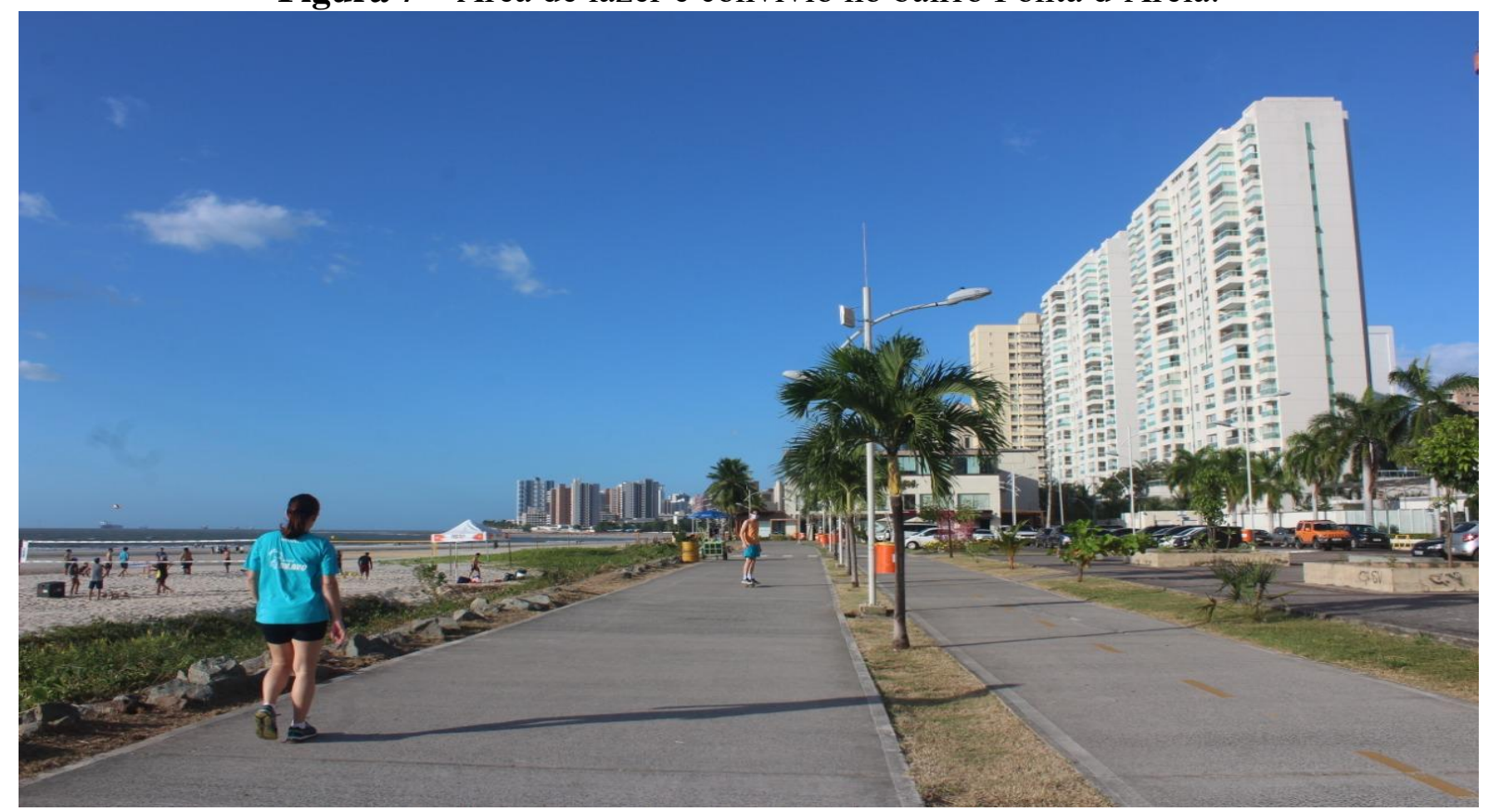

Fonte: Autor (2021).

Observa-se na figura 7, a estrutura ao longo do calçadão do bairro que leva até o espigão costeiro, onde encontram-se espaços para pedestres, ciclistas e áreas de convivências, existem também árvores, além da proximidade com a praia, fatores importantes para atrair inúmeros visitantes ao local. Já no próprio espigão, também identificamos pessoas fazendo uso de sua estrutura em algumas atividades, a figura 8 demonstra a seguir.

Figura 8 - Ciclista no espigão costeiro da Ponta d'Areia.

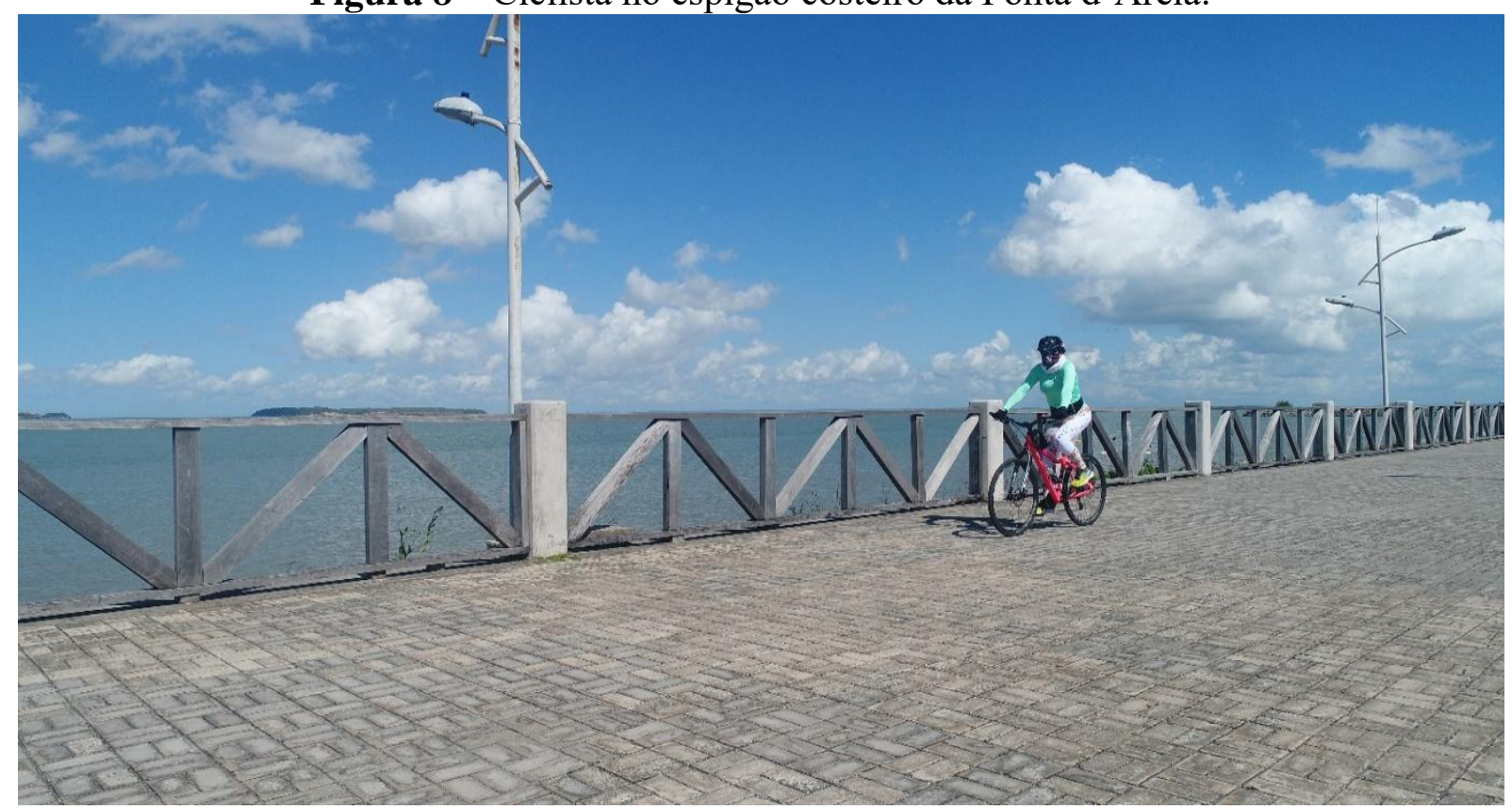

Fonte: Autor (2021). 
Como pode ser verificado na figura 8, a prática de exercícios é comum no espigão costeiro, isto em virtude, do ambiente possuir um espaço amplo e seguro para os seus frequentadores. Essa realidade expõe a implementação de uma nova dinâmica de uso do espaço, que agora proporciona aos seus visitantes espaços de convivência, prática de atividades físicas, área de lazer e outros (MARTINS, 2018).

O surgimento do espigão costeiro agregou ainda mais para o processo de valorização que já estava em andamento no bairro Ponta d'Areia, sendo mais um atrativo para as pessoas que visitam o local. Em razão de também contribuir para valorizar a área, o espigão tornou-se um importante elemento para os investidores da iniciativa privada que atuam no local (MARQUES, 2021). Pois, com a sua construção, o local ganha um espaço ímpar na cidade, e torna-se ainda mais diferenciado dos demais bairros, estes fatores colaboram com os anseios dos grupos hegemônicos que investem naquele território.

Como foi exposto, a dinâmica de uso e ocupação foi alterada no bairro Ponta d'Areia, em função também do surgimento do espigão costeiro. Dessa forma, não somente a configuração paisagística se modificou, mas também outros fatores, como a presença constante de visitantes e a rede comercial que se instaurou no lugar, o local é atualmente um dos cartões postais da capital maranhense.

\section{Considerações finais}

Com a construção do estudo constatou-se que o espigão costeiro do bairro Ponta d'Areia cumpriu o seu papel inicial, percebe-se atualmente que existe um grande banco de areia formado a partir dos resultados de sua intervenção na área, protegendo assim o local do intenso processo erosivo. Nota-se também que a faixa de areia da praia foi preservada.

Destacamos também a alteração na dinâmica socioespacial do lugar, pois, o uso do turístico e de lazer do espigão trouxeram novos usos àquele espaço. Em virtude dessa nova caracterização do local, encontram-se atualmente nas proximidades do espigão espaços para caminhadas; ciclovias; parques de diversão; museu; café e outros.

Portanto, em função dessa nova dinâmica, o espigão costeiro através de sua transformação em ponto turístico, passou a agregar valor ao espaço, mas também a ofertar 
inúmeros serviços à população, fatores que o fazem ser um dos importantes pontos de visitações atualmente na cidade.

Com relação à sociedade, destaca-se que para a população local o espaço é mais um atrativo de lazer e mais um ponto turístico para aqueles que conhecem São Luís. Porém, o espigão é uma obra pública que foi realizada através de consideráveis valores para o Estado, portanto, algumas reflexões de cunho mais crítico também precisam ser elencadas.

A execução da obra se contrasta com uma realidade distinta de outros espaços da cidade, sobretudo nas áreas de habitação das classes populares, onde intervenções de menor magnitude do que a construção de um espigão costeiro, não são efetuadas. Pelo contrário, o poder público se mostra ausente.

Ambientes de lazer e pontos turísticos são sempre pontos positivos para a população, mas a implementação seletiva desses elementos, ainda colaborando com um processo de valorização socioespacial já em curso que tende a beneficiar também a iniciativa privada atuante naquela área da cidade, deve ser melhor refletido.

O ideal seria a execução de intervenções do poder público de forma ampla, visando atender as necessidades das mais diversas classes sociais que integram a cidade de São Luís. Tanto das que necessitam da construção de um espigão costeiro, até aquelas que possuem anseios mais básicos, do ponto de vista financeiro.

\section{Referências}

COELHO, Gláuber Tulio Fonseca; SALES, Layse Lorena Neves. Ocupação do espaço urbano: observações históricas e a expansão da Península da Ponta D'areia em São Luís (MA) entre os anos de 2004 e 2016. Social Evolution, v. 1, n. 1, p. 16-26, 2017.

Facebook. Perfil São Luís antes e depois. 2020. Disponível em:https://ptbr.facebook.com/pages/category/Book/S\%C3\%A3o-Luis-de-Antes-e-Depois$\underline{1412370035732389 />}$ acesso em setembro de 2020.

G1MA. Espigão costeiro da Ponta d'Areia começa a receber obras de urbanização. 2014. Disponível em: http://g1.globo.com/ma/maranhao/jmtv-2edicao/videos/v/espigao-costeiro-daponta-dareia-comeca-a-receber-obras-de-urbanizacao/2484275/> acesso em novembro de 2020.

GIL, Antônio Carlos. Como elaborar projetos de pesquisa. 4.ed. São Paulo: Atlas, 2006.

MARQUES, Matheus Andrade. Transformação do espaço urbano: análise socioespacial e paisagística da Península da Ponta d'Areia em São Luís (Maranhão, Brasil). Dissertação 
(Mestrado) 125 f. São Luís: Curso de Geografia, Natureza e Dinâmica do Espaço, Universidade Estadual do Maranhão, 2021.

MARTINS, Gabriela Souza. São Luís Moderna e Contraditória: resistência e permanência na Ilhinha e Ponta d'Areia. Dissertação (Mestrado) 140 f. São Luís: Curso em Desenvolvimento Socioespacial e Regional, Universidade Estadual do Maranhão, 2018.

PIOVESAN, A.; TEMPORINI, E. R. Pesquisa exploratória: Procedimento metodológico para o estudo de fatores humanos no campo da saúde pública. Revista Saúde Pública. 29(4), 318 $-325.1995$.

PRADO, Barbara Irene Wasinski. Paisagem Urbana de São Luís: transformação das formas e arranjos naturais na Ponta d'Areia. São Luís: Editora BIWP, 2016.

SECRETARIA DE INFRAESTRUTURA DO MARANHÃO. SINFRA, 2014. Disponível em:http://sinfra.ma.gov.br/2017/03/21/servicos-de-manutencao-sao-realizadospermanentemente-no-espigao-costeiro-em-sao-luis/> acesso em Janeiro de 2020.

SILVA, Thaynara Correia. Apropriação de Praias por Empreendimentos do Setor Hoteleiro sob a Égide do Direito Brasileiro: Estudo do caso da Península da Ponta d'Areia São Luís, MA. Trabalho de Conclusão de Curso, Universidade Federal do Maranhão, 2018. 